\title{
Article \\ Characterisation of Permanent Deformation Behaviour of Asphalt Mix Based on a Combined Elastic Plastic (CEP) Parameter
}

\author{
Abhirup B. Roy-Chowdhury ${ }^{1, *} \mathbb{C}$, Mofreh F. Saleh ${ }^{1}$ and Miguel Moyers-Gonzalez ${ }^{2}$ \\ 1 Pavement Research Laboratory, Department of Civil and Natural Resources Engineering, University of \\ Canterbury, Private Bag 4800, Christchurch 8140, New Zealand; mofreh.saleh@canterbury.ac.nz \\ 2 Department of Mathematics and Statistics, University of Canterbury, Private Bag 4800, \\ Christchurch 8140, New Zealand; miguel.moyersgonzalez@canterbury.ac.nz \\ * Correspondence: abhirup.basuroychowdhury@pg.canterbury.ac.nz
}

check for

updates

Citation: Roy-Chowdhury, A.B.; Saleh, M.F.; Moyers-Gonzalez, M. Characterisation of Permanent Deformation Behaviour of Asphalt Mix Based on a Combined Elastic Plastic (CEP) Parameter. Infrastructures 2021, 6, 183. https://doi.org/10.3390/ infrastructures6120183

Academic Editor: Hugo Silva

Received: 15 November 2021 Accepted: 17 December 2021 Published: 20 December 2021

Publisher's Note: MDPI stays neutral with regard to jurisdictional claims in published maps and institutional affiliations.

Copyright: (c) 2021 by the authors. Licensee MDPI, Basel, Switzerland. This article is an open access article distributed under the terms and conditions of the Creative Commons Attribution (CC BY) license (https:/ / creativecommons.org/licenses/by/ $4.0 /)$.

\begin{abstract}
Permanent deformation or rutting is a major mode of failure in Hot Mix Asphalt (HMA) pavements. The binder used in the asphalt mixture plays an important role in the rutting resistance performance of the mixture. Currently, the Superpave rutting parameter and a more advanced test called multiple stress creep and recovery (MSCR) are the most widely used tests for rutting characterisation of asphalt binders. However, they both have their own merits and demerits. This study was undertaken to introduce a combined Elastic-Plastic (CEP) parameter as an additional binder rheological rutting parameters. The study also aimed at investigating the applicability and potential of this parameter to supplement the existing binder rheological parameters to characterise the properties of asphalt binder related to HMA rutting performance. Additionally, the correlations of the binder rheological parameters with the asphalt mix rutting parameters generated by the dynamic creep and the dynamic modulus tests were investigated. For the polymer-modified binders, StyreneButadiene-Styrene (SBS) was added to the PG 70-16 binder at two concentration levels (4, and 6\% by the mass of the binder). A dense-graded HMA AC 14 was tested in the Dynamic Modulus (DM) and Dynamic Creep (DC) tests for evaluating the rutting performance. The CEP parameter was found to be much more reliable than the traditional $G^{*} / \sin (\delta)$ and the non-recoverable creep compliance $\left(J_{n r}\right)$ parameters for evaluating the rutting behaviour of polymer modified asphalt binders, evident from better correlations of CEP with the asphalt mix performance. Unlike Jnr, the CEP parameter revealed a wider range of values, which is comparable with asphalt mixture test results.
\end{abstract}

Keywords: Hot Mix Asphalt (HMA); polymer modification; rheology; permanent deformation; asphalt binder; Multiple Stress Creep Recovery (MSCR)

\section{Introduction}

Permanent deformation in the form of rutting is a critical failure in asphalt or flexible pavements [1]. Aggregates and binder are the primary components of asphalt pavements, and along with the aggregate gradation, degree of compaction, temperature and loading rate, the binder plays a crucial role in the rutting resistance and stiffness of asphalt mixtures used in the pavements [2-4]. Rutting in Hot Mix Asphalt (HMA), which is used as the surfacing layer in flexible pavements, is caused by the combination of densification and shear deformation, and the latter causes the severe form of the distress [3].

Various laboratory tests are used to evaluate and analyse the rutting resistance of asphalt mixtures in laboratory, which may help predict field performance of asphalt concrete pavements. These tests include dynamic modulus (DM), static creep (SC), dynamic creep test (DC), triaxial test and the wheel trackers [5]. The National Cooperative Highway Research Program (NCHRP) Project 9-12 recommends DM, Flow Time (FT) and Flow Number (FN) tests, collectively called simple performance test (SPT) for evaluating the 
rutting resistance of asphalt mixtures [6]. Dynamic modulus has been long used for laboratory characterisation of HMA mixtures in terms of their stiffness and rutting resistance [7]. Flow number from the dynamic creep test, which considers the shear behaviour of asphalt mixtures, has also been widely used for laboratory evaluation of rutting resistance [4].

The correct selection of binder plays an important role in the asphalt mixture performance against rutting [5]. For the characterisation of the asphalt binder properties related to permanent deformation or rutting, the high-temperature grade is used by the Superpave performance grading system. The determination of high-temperature grade is based on the parameter $G^{*} / \sin (\delta)$, where $\left(G^{*}\right)$ is the complex shear modulus and $(\delta)$ is the phase angle, which are measured in the Dynamic Shear Rheometer (DSR) test. However, this parameter has shown insufficiency for both unmodified and modified binders, and often shows poor correlation with field performance [1]. To address this shortcoming, Shenoy (2001) introduced a new parameter: $G^{*} /\left(1-\left(1 / \tan (\delta)^{*} \sin (\delta)\right)\right.$, which considers the elastic component of binder and hence can be beneficial in determining the rutting resistance of both unmodified and modified binders [8-10]. However, none of the parameters, $G^{*} / \sin (\delta)$, and $G^{*} /(1$ $-\left(1 / \tan (\delta)^{*} \sin (\delta)\right)$ is able to simulate the behaviour of binders under high stress conditions such as those in the field [11]. Therefore, the Federal Highway Administration (FHWA) developed a new PG binder test called the Multiple Stress Creep and Recovery (MSCR) test to characterise the asphalt binder properties related to HMA rutting [7]. While several studies $[1,12,13]$ have shown that the MSCR test has a better correlation with HMA rutting performance, the parameters $G^{*}$ and $\delta$ measured by the DSR still form the basis of the current specifications. In light of this, $G^{*} / \sin (\delta)$ leads to overdesign (which indicates that it underestimates rutting resistance, especially of the polymer modified binders), resulting in higher material costs [14]. However, it is still possible to obtain excellent correlations between $G^{*} / \sin (\delta)$ of a group of similar asphalt binders and asphalt mixes (i.e., comparing the asphalt binders within same polymer family and the corresponding asphalt mixtures) within a wide range of temperatures. It is also feasible to predict the rutting resistance of asphalt mixtures (tested at $50^{\circ} \mathrm{C}$ ) from $G^{*} / \sin (\delta)$ of a mixed set of unmodified and polymermodified binders when tested at a slightly lower temperature, such as $40{ }^{\circ} \mathrm{C}$ [5]. On the other hand, despite the MSCR test being a significant step towards the improvement of laboratory evaluation of asphalt binder field performance, some concerns related to the test were identified during the literature search. Several research observed that the standard MSCR results $\left(J_{n r 3.2}\right.$ and percent recovery $\left.R_{3.2}\right)$ did not particularly correlate well with asphalt mix rutting parameters from the Repeated Load Permanent Deformation (RLPD) and Hamburg Wheel Tracker Test (HWTT) [15-17]. Furthermore, some research showed that for Polymer Modified Bitumen (PMB) family, $G^{*} / \sin (\delta)$ provides better correlation with corresponding asphalt mixture results than $J_{n r}$ [5]. Additionally, it can be said that, although several research did successfully prove that $J_{n r}$ correlates better with the HMA rutting performance than $G^{*} / \sin (\delta)$, a considerable overlapping or near-identical values can be observed in the $J_{n r}$ values of the asphalt binders, despite the binders being vastly different from each other $[1,18]$. This can often be confusing and hinder true segregation of asphalt binders from one another.

Therefore, a further evaluation of the traditional and the new binder rheological parameters $\left(G^{*} / \sin (\delta)\right.$ and $\left.J_{n r}\right)$ through an empirically derived parameter was attempted in this study, considering the merits of individual parameters, and thereby investigate its potential to supplement the existing binder rheological parameters to characterise the properties of asphalt binder related to HMA rutting performance. This derived parameter is a combined elastic-plastic (CEP) parameter suggested by the authors in this study, the details of which can be found in following sections. The use of the CEP parameter takes a prominent part in the current study. 


\section{Research Objectives and Scope of Study}

The main objectives of the current study are:

1. The study aims to introduce the CEP parameter as one of the binder rheological rutting parameters. This study was also undertaken to investigate on the applicability and potential of this parameter to supplement the existing binder rheological parameters to characterise the properties of asphalt binder related to HMA rutting performance.

2. To compare and correlate the permanent deformation characteristics of the asphalt mixtures evaluated in Dynamic Modulus (DM) and Dynamic Creep (DC) tests with the three binder rheological parameters discussed earlier.

\section{Rheological Properties Measured by the Dynamic Shear Rheometer (DSR)}

The complex shear modulus of asphalt binder $G^{*}$, and the phase angle $\delta$ are measured by the DSR device at high temperature to determine the viscoelastic behaviour of the asphalt binder and therefore, its contribution to the permanent deformation of the asphalt mix. It is evident from past research that higher $G^{*}$ and lower $\delta$ indicate better binder performance in light of permanent deformation [1]. The MSCR test uses the well-known creep and recovery concept to characterise the rutting potential of the asphalt binder, where the binder is subjected to a one-second creep loading. After the removal of the load, the binder sample is allowed to recover for $9 \mathrm{~s}$. The test initially applies $0.1 \mathrm{kPa}$ (lower stress) for 10 cycles of creep/recovery, after which a stress of $3.2 \mathrm{kPa}$ is applied for 10 additional cycles [1]. A typical output of this test is the non-recoverable compliance $\left(J_{n r}\right)$. The high temperature parameter test and the MSCR test were conducted according to ASTM D717515 and ASTM D7405-15 respectively [19,20]. The authors in this research considered the results of both the DSR and MSCR to determine a combined elastic-plastic (CEP) parameter as shown by Equation (1):

$$
\text { CEP parameter }=\frac{G^{*} / \sin (\delta)}{J_{n r}}
$$

The parameter combines both the elastic component represented by $G^{*} / \sin (\delta)$ which needs to be maximised and the plastic component $J_{n r}$ which needs to be minimised. This way, the individual merits of the said parameters discussed in the previous section can be utilised, and the individual demerits can be compensated. The higher the CEP, the better the binder permanent deformation resistance.

\section{Asphalt Mixture Tests}

\subsection{Dynamic Modulus (DM) Test}

Dynamic modulus $\left(\left|E^{*}\right|\right)$ is a non-destructive test that involves the application of uniaxial repeated loading on asphalt mixture cylindrical samples at various temperatures and frequencies, and the resilient strain of the specimens are measured. The dynamic modulus test in this study was based on the NCHRP Report 614 test procedure [21]. Four temperatures of $4.4,21.1,37.8$ and $54.4^{\circ} \mathrm{C}$ and five frequencies of $10,5,1,0.5$ and $0.1 \mathrm{~Hz}$ were utilised in this study. Three on-specimen Linear Variable Differential Transformers (LVDTs) with gauge length of $100 \mathrm{~mm}$ were used in the DM test setup. To avoid damaging specimens during the test, they were tested from the highest frequency to the lowest frequency and the lowest temperature to the highest temperature. The Pellinen and Witczak [22] time-temperature superposition sigmoidal model was utilised to construct $\left|E^{*}\right|$ master-curves for the binders. Figure 1 shows the dynamic modulus test setup. 


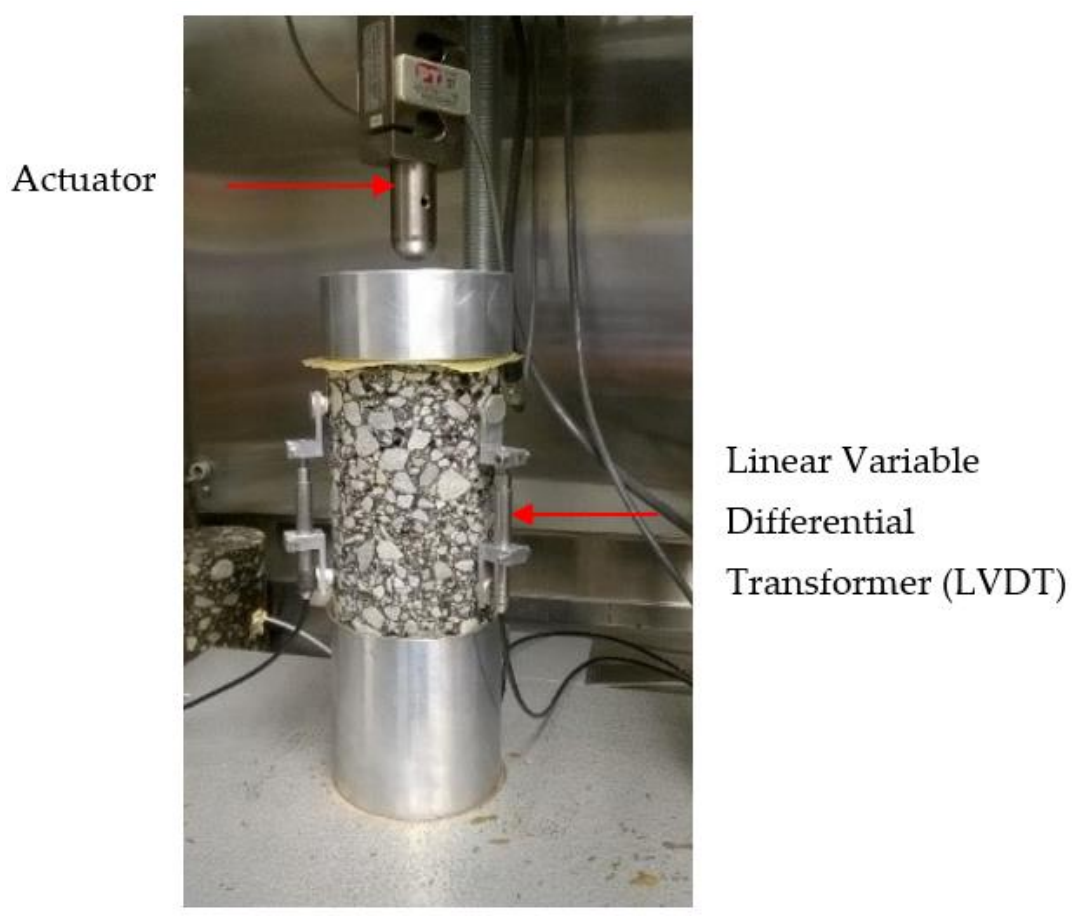

Figure 1. Dynamic modulus test setup.

\subsection{Dynamic Creep (DC) Test}

Dynamic creep test is one of the simple performance tests (SPT) recommended by NCHRP report 465 to evaluate permanent deformation resistance of asphalt mixture by measuring the cumulative permanent strain. Some research showed an approach where the DC test was conducted right after the DM test on the same specimens at the same temperatures as the current study [23,24]. A previous research investigated the level of damage taking place in the DM and DC tests using X-ray CT and to characterise the heterogeneous characteristics of asphalt mixtures under loading [25]. Based on the results, it was determined that the damage taking place in the DM test is minimal and homogeneous while the damage taking place in the DC test is significant and heterogeneous. These results confirm that the assumption of minimal or insignificant damage taking place in the dynamic modulus test is valid. Therefore, the same cylindrical samples tested in the DM test were utilised for the unconfined Dynamic Creep test, where they were subjected to a repeated axial haversine loading pulse of $0.1 \mathrm{~s}$ every $1 \mathrm{~s}$ under a deviatoric stress of $207 \mathrm{kPa}$, as recommended by NCHRP Report 465 [6]. The termination parameters were chosen as 10,000 loading cycles or 54,000 micro-strain, whichever occurs first. The typical output of the Dynamic Creep test is Flow Number (FN), which depicts the onset of the tertiary flow. The test procedure was followed according to AASHTO T 378 standard [26].

\section{Materials and Experimental Program}

\subsection{Asphalt Binders}

A total of five type of asphalt binders were utilised in this study. Three grades of the unmodified asphalt binders were used: PG 64-16, PG 70-16 and PG 76-16. The polymer modified binders were designated as PMB 4\% SBS and PMB $6 \%$ SBS. The polymer modification was conducted utilising the base binder PG 70-16 modified by Styrene-Butadiene-Styrene (SBS) at $4 \%$ and $6 \%$ by mass of the pure binder. SBS concentrations of $3-6 \%$ is common in New Zealand, and are used in very heavily trafficked areas. Additionally, several studies have been conducted with 3-7\% of SBS added to the control binder [14,17,27-29]. Therefore, the SBS concentrations used in this study ( $4 \%$ and $6 \%$ by weight) fall within this range. As reported in the literature, 5\% SBS by weight of the bitumen is the optimum percent of the SBS that is used to modify binder and has the best influence on performance 
properties of mixture [14]. In addition, it was important for the purpose of investigating the current rheological parameters and their ability to characterise polymer modified binders, considering a wide range of modification percentages.

The SBS used in this paper is Styrene, 1, 3-butadiene polymer (radial); and its properties are shown in Table 1.

Table 1. Properties of SBS.

\begin{tabular}{cccc}
\hline Appearance & Molecular Weight & $\begin{array}{c}\text { Relative Density } \\
\left(\mathbf{g} / \mathbf{c m}^{3}\right) \text { at } 25{ }^{\circ} \mathbf{C}\end{array}$ & Melting Point $\left({ }^{\circ} \mathbf{C}\right)$ \\
\hline White; solid & $>10,000$ & $0.91-0.97$ & $160-200$ \\
\hline
\end{tabular}

\subsection{Asphalt Mixtures}

A dense graded HMA AC 14 with nominal maximum aggregate size (NMAS) of 14 $\mathrm{mm}$ and target voids in total mix (VTM) of $4.0 \pm 1.0 \%$ was tested at temperatures 4.4 , $21.1,37.8$, and $54.4{ }^{\circ} \mathrm{C}$ in the DM test and at $60{ }^{\circ} \mathrm{C}$ in the DC test. For both cases, the asphalt mix cylindrical samples were conditioned at respective temperatures according to the relevant report and standard [21,26]. A total of 10 cylindrical samples (five mixes with two replicates each) of $150 \mathrm{~mm}$ in height and $100 \mathrm{~mm}$ in diameter were compacted and tested. The mixing and compaction temperatures for different binders were chosen according to Australian and New Zealand standards [30,31]. The asphalt mixtures were short-term aged for one hour before compaction. The aggregate gradation of the AC 14 mix is shown in Figure 2.

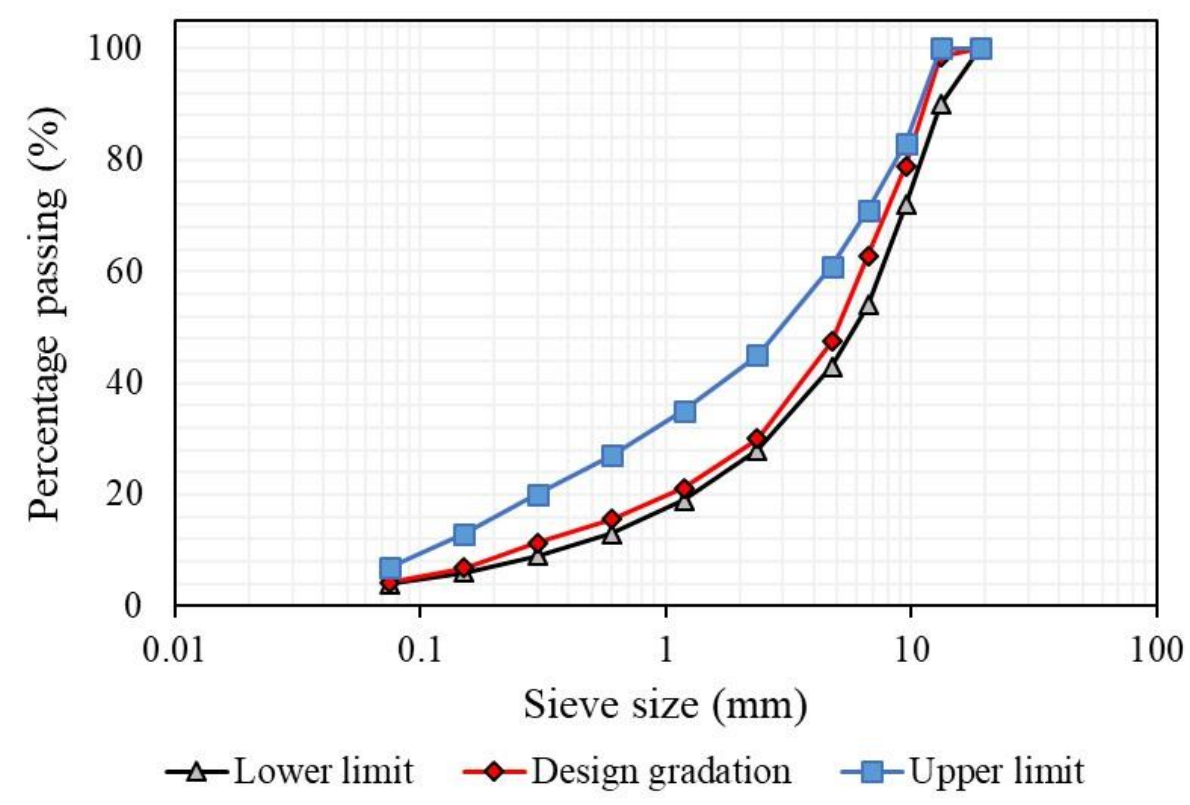

Figure 2. Gradation curve for AC 14.

The binder rheological test conditions and specifications used in this study are summarised in Table 2. Figure 3 shows specimen preparations and 25-mm parallel plate geometry for the DSR and MSCR tests of the asphalt binder. Two replicates were considered for each binder type and testing, and at each temperature and stress level. 
Table 2. Test description and specifications.

\begin{tabular}{lll}
\hline Test & DSR High-Temperature Test & MSCR \\
\hline Size of specimen & 25-mm $\phi$ with 1-mm gap, & 25-mm $\phi$ with 1-mm gap, \\
Mode of loading & asphalt binder specimen & asphalt binder specimen \\
Temperature & Oscillation at $1.59 \mathrm{~Hz}$ & $1 \mathrm{~s}$. loading; 9 s. rest \\
Output & $64,70,76{ }^{\circ} \mathrm{C}$ & $64,70,76^{\circ} \mathrm{C}$ \\
Standard & High temperature grading, & $J_{n r}$ (non-recoverable creep \\
\hline
\end{tabular}

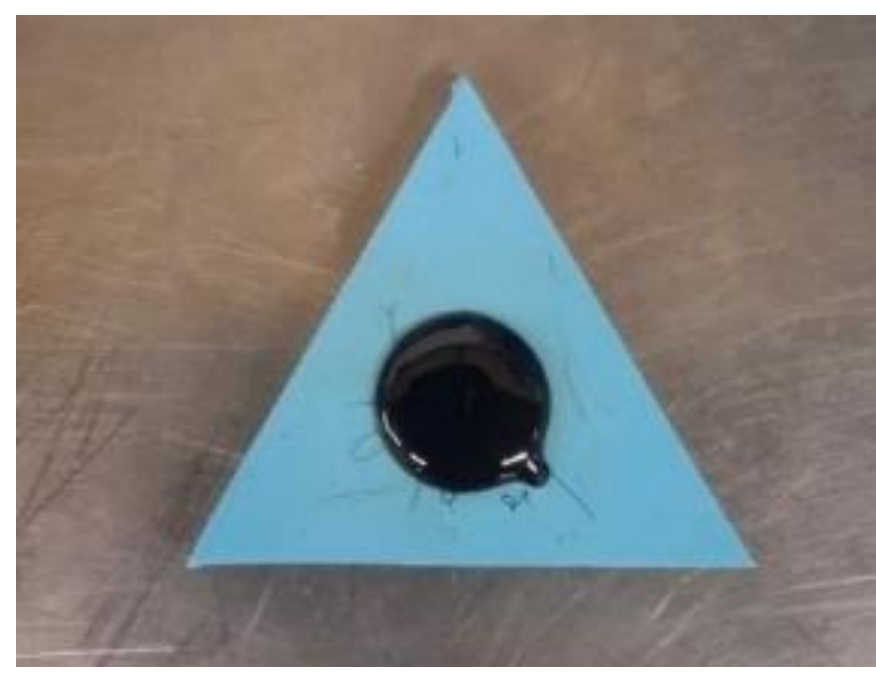

(a)

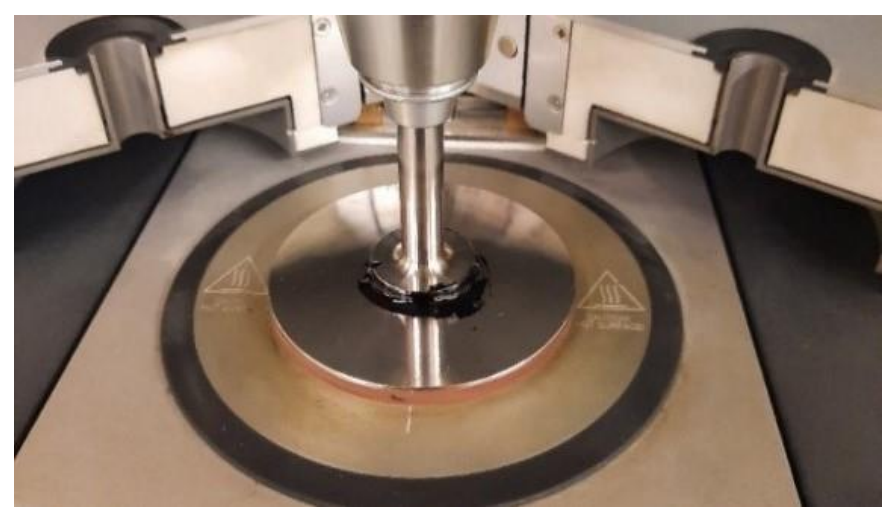

(b)

Figure 3. (a) Specimen preparations, and (b) 25-mm parallel plate geometry for the DSR and MSCR tests.

\section{Asphalt Binder Rheological Test Results \\ 6.1. Binder Rheology}

Table 3 shows the $G^{*} / \sin (\delta)$ for the unaged and RTFO or short-term aged binders at different temperatures. It can be observed from the data presented, $G^{*} / \sin (\delta)$ decreased with the increase in temperature for all the binders. The high-temperature test results for the unaged modified binders revealed that $4 \%$ SBS achieved a high performance grade of PG 76, while PMB 6\% SBS achieved a grade of PG 88. It can be noted from the results that the addition of SBS to the control binder PG 70-16 generally increased the stiffness of the binder. Moreover, $G^{*} / \sin (\delta)$ values after RTFO-aging were found to be higher than those before RTFO-aging, as may be expected. The ranking based on $G^{*} / \sin \delta$ (unaged) 
and $G^{*} / \sin \delta$ (RTFO-aged) at $64{ }^{\circ} \mathrm{C}$ were found to be in the order PMB 6\% SBS > PG 76-16 $>$ PMB 4\% SBS > PG 70-16 > PG 64-16 and PG 76-16 > PMB 6\% SBS > PMB 4\% SBS > PG 70-16 > PG 64-16, respectively. The ranking reveals inconsistency and conflict, which may be attributed to the non-linear characteristics of the polymer modified binders and their different aging properties. This essentially indicates that $G^{*} / \sin \delta$ solely cannot characterise polymer modified binders.

Table 3. DSR high-temperature test results of unaged and RTFO-aged binders.

\begin{tabular}{|c|c|c|c|}
\hline Binder & Temperature & $G^{*} / \sin \delta(\mathbf{k P a})$ of Unaged Binders & SD \\
\hline \multirow{4}{*}{ PG 64-16 } & $64{ }^{\circ} \mathrm{C}$ & 1.05 & 0.12 \\
\hline & $70{ }^{\circ} \mathrm{C}$ & 0.54 & 0.04 \\
\hline & $76^{\circ} \mathrm{C}$ & 0.30 & 0.04 \\
\hline & $64{ }^{\circ} \mathrm{C}$ & 2.20 & 0.07 \\
\hline \multirow[t]{3}{*}{ PG 70-16 } & $70{ }^{\circ} \mathrm{C}$ & 1.09 & 0.03 \\
\hline & $76^{\circ} \mathrm{C}$ & 0.57 & 0.02 \\
\hline & $64{ }^{\circ} \mathrm{C}$ & 4.46 & 0.99 \\
\hline \multirow[t]{3}{*}{ PG 76-16 } & $70{ }^{\circ} \mathrm{C}$ & 2.15 & 0.47 \\
\hline & $76^{\circ} \mathrm{C}$ & 1.10 & 0.21 \\
\hline & $64{ }^{\circ} \mathrm{C}$ & 3.93 & 0.49 \\
\hline \multirow[t]{3}{*}{ PMB 4\% SBS } & $70{ }^{\circ} \mathrm{C}$ & 2.06 & 0.19 \\
\hline & $76^{\circ} \mathrm{C}$ & 1.14 & 0.03 \\
\hline & $64{ }^{\circ} \mathrm{C}$ & 7.22 & 0.59 \\
\hline \multirow[t]{2}{*}{ PMB 6\% SBS } & $70{ }^{\circ} \mathrm{C}$ & 4.73 & 0.45 \\
\hline & $76^{\circ} \mathrm{C}$ & 3.40 & 0.31 \\
\hline \multirow[t]{2}{*}{ Binder } & Temperature & $G^{*} / \sin \delta(\mathrm{kPa})$ of RTFO-Aged Binders & SD \\
\hline & $64^{\circ} \mathrm{C}$ & 2.80 & 0.21 \\
\hline \multirow[t]{3}{*}{ PG 64-16 } & $70{ }^{\circ} \mathrm{C}$ & 1.30 & 0.12 \\
\hline & $76{ }^{\circ} \mathrm{C}$ & 0.60 & 0.11 \\
\hline & $64{ }^{\circ} \mathrm{C}$ & 5.29 & 0.37 \\
\hline \multirow[t]{3}{*}{ PG 70-16 } & $70{ }^{\circ} \mathrm{C}$ & 2.50 & 0.23 \\
\hline & $76^{\circ} \mathrm{C}$ & 1.25 & 0.13 \\
\hline & $64{ }^{\circ} \mathrm{C}$ & 12.10 & 0.13 \\
\hline \multirow[t]{3}{*}{ PG 76-16 } & $70{ }^{\circ} \mathrm{C}$ & 5.69 & 0.04 \\
\hline & $76^{\circ} \mathrm{C}$ & 2.76 & 0.05 \\
\hline & $64{ }^{\circ} \mathrm{C}$ & 9.30 & 0.81 \\
\hline \multirow[t]{3}{*}{ PMB 4\% SBS } & $70{ }^{\circ} \mathrm{C}$ & 4.81 & 0.21 \\
\hline & $76^{\circ} \mathrm{C}$ & 2.54 & 0.04 \\
\hline & $64{ }^{\circ} \mathrm{C}$ & 11.35 & 0.30 \\
\hline \multirow[t]{2}{*}{ PMB 6\% SBS } & $70{ }^{\circ} \mathrm{C}$ & 6.24 & 1.10 \\
\hline & $76^{\circ} \mathrm{C}$ & 3.75 & 0.11 \\
\hline
\end{tabular}

Note. SD: Standard Deviation

The MSCR test results of the short-term aged binders at 64,70 and $76{ }^{\circ} \mathrm{C}$, and conducted at $0.1 \mathrm{kPa}$ and $3.2 \mathrm{kPa}$ stress levels respectively are presented in Table 4 . It can be clearly seen that for the polymer modified binders, PMB 6\% SBS binder performed better than PMB 4\% SBS at every temperature for both lower and higher stress levels, as expected. The ranking based on both $J_{n r}$ at $0.1 \mathrm{kPa}$ and $3.2 \mathrm{kPa}$ at $64{ }^{\circ} \mathrm{C}$ was found to be in the order PMB 6\% SBS > PMB 4\% SBS > PG 76-16 > PG 70-16 > PG 64-16. However, while it is expected that $J_{n r}$ is capable of characterising polymer modified binders correctly, it can be seen that the difference in $J_{n r}$ values of PMB $4 \%$ SBS and $6 \%$ SBS at $64{ }^{\circ} \mathrm{C}$ at $3.2 \mathrm{kPa}$ and at higher temperatures is marginal. Therefore, to address this, the ratio of $G^{*} / \sin (\delta)$ to $J_{n r}$, termed as CEP, was calculated for the RTFO-aged binders at different temperatures and stress levels. The CEP results are also presented in Table 4 . The calculations for the polymer modified binders suggested that the said ratio is greatest for PMB 6\% SBS binder, followed by PMB 4\% SBS. Furthermore, a decrease in trend is observed with an increase in stress level from $0.1 \mathrm{kPa}$ to $3.2 \mathrm{kPa}$. As can be clearly observed that CEP could capture the polymer modification, evident from the clear distinction in the CEP values especially 
between PMB 4\% and 6\% SBS. As discussed earlier, this was not evident with $J_{n r}$, which showed no clear difference between PMB 4\% SBS and PMB 6\% SBS respectively, which can be confusing. This indicates that the CEP parameter could serve as an additional rheological parameter to rank and distinguish unmodified and polymer modified binders.

Table 4. $J_{n r}$ and CEP parameter results of the asphalt binders.

\begin{tabular}{|c|c|c|c|c|c|}
\hline \multirow[b]{2}{*}{ Binder } & \multicolumn{5}{|c|}{$J_{n r}\left(\mathrm{kPa}^{-1}\right)$ from MSCR Test } \\
\hline & Temperature & \multicolumn{4}{|c|}{ Stress and Corresponding Standard Deviation (SD) } \\
\hline \multirow{5}{*}{ PG 64-16 } & & $0.1 \mathrm{kPa}$ & $\mathrm{SD}$ & $3.2 \mathrm{kPa}$ & SD \\
\hline & $64{ }^{\circ} \mathrm{C}$ & 3.37 & 0.23 & 4.00 & 0.42 \\
\hline & $70{ }^{\circ} \mathrm{C}$ & 7.32 & 1.47 & 8.62 & 1.68 \\
\hline & $76{ }^{\circ} \mathrm{C}$ & 15.94 & 2.13 & 18.77 & 2.28 \\
\hline & $64{ }^{\circ} \mathrm{C}$ & 1.56 & 0.10 & 1.99 & 0.15 \\
\hline \multirow[t]{3}{*}{ PG 70-16 } & $70{ }^{\circ} \mathrm{C}$ & 3.42 & 0.76 & 4.33 & 1.04 \\
\hline & $76^{\circ} \mathrm{C}$ & 7.18 & 1.92 & 9.00 & 2.47 \\
\hline & $64^{\circ} \mathrm{C}$ & 0.61 & 0.14 & 0.76 & 0.24 \\
\hline \multirow[t]{3}{*}{ PG 76-16 } & $70{ }^{\circ} \mathrm{C}$ & 1.44 & 0.47 & 1.82 & 0.48 \\
\hline & $76^{\circ} \mathrm{C}$ & 3.22 & 0.98 & 4.18 & 1.10 \\
\hline & $64{ }^{\circ} \mathrm{C}$ & 0.33 & 0.01 & 0.54 & 0.17 \\
\hline \multirow[t]{3}{*}{ PMB $4 \%$ SBS } & $70{ }^{\circ} \mathrm{C}$ & 0.64 & 0.23 & 1.52 & 0.27 \\
\hline & $76{ }^{\circ} \mathrm{C}$ & 1.92 & 0.55 & 3.68 & 0.44 \\
\hline & $64{ }^{\circ} \mathrm{C}$ & 0.17 & 0.10 & 0.40 & 0.02 \\
\hline \multirow[t]{2}{*}{ PMB 6\% SBS } & $70{ }^{\circ} \mathrm{C}$ & 0.52 & 0.16 & 1.03 & 0.06 \\
\hline & $76^{\circ} \mathrm{C}$ & 1.34 & 0.32 & 2.55 & 0.13 \\
\hline \multicolumn{6}{|c|}{ Combined Elastic-Plastic Parameter (with $G^{*} / \sin (\delta)$ of RTFO-Aged Binder) } \\
\hline \multirow[t]{2}{*}{ Binder } & Temperature & \multicolumn{4}{|c|}{ Stress and corresponding Standard Deviation (SD) } \\
\hline & & $0.1 \mathrm{kPa}$ & $\mathrm{SD}$ & $3.2 \mathrm{kPa}$ & SD \\
\hline \multirow{4}{*}{ PG 64-16 } & $64^{\circ} \mathrm{C}$ & 0.83 & 0.00 & 0.70 & 0.02 \\
\hline & $70^{\circ} \mathrm{C}$ & 0.18 & 0.02 & 0.15 & 0.01 \\
\hline & $76^{\circ} \mathrm{C}$ & 0.04 & 0.00 & 0.03 & 0.00 \\
\hline & $64{ }^{\circ} \mathrm{C}$ & 3.39 & 0.02 & 2.66 & 0.01 \\
\hline \multirow[t]{3}{*}{ PG 70-16 } & $70^{\circ} \mathrm{C}$ & 0.73 & 0.07 & 0.58 & 0.06 \\
\hline & $76^{\circ} \mathrm{C}$ & 0.17 & 0.02 & 0.14 & 0.02 \\
\hline & $64^{\circ} \mathrm{C}$ & 19.81 & 3.62 & 15.90 & 3.60 \\
\hline \multirow[t]{3}{*}{ PG 76-16 } & $70{ }^{\circ} \mathrm{C}$ & 3.95 & 0.86 & 3.13 & 0.59 \\
\hline & $76^{\circ} \mathrm{C}$ & 0.86 & 0.17 & 0.66 & 0.12 \\
\hline & $64{ }^{\circ} \mathrm{C}$ & 28.48 & 1.16 & 17.34 & 2.71 \\
\hline \multirow[t]{3}{*}{ PMB $4 \%$ SBS } & $70{ }^{\circ} \mathrm{C}$ & 7.51 & 1.60 & 3.17 & 0.34 \\
\hline & $76^{\circ} \mathrm{C}$ & 1.32 & 0.25 & 0.69 & 0.06 \\
\hline & $64^{\circ} \mathrm{C}$ & 67.00 & 15.03 & 28.13 & 2.11 \\
\hline \multirow[t]{2}{*}{ PMB $6 \%$ SBS } & $70{ }^{\circ} \mathrm{C}$ & 11.93 & 1.15 & 6.05 & 0.67 \\
\hline & $76{ }^{\circ} \mathrm{C}$ & 2.80 & 0.56 & 1.47 & 0.11 \\
\hline
\end{tabular}

For the purpose of observing this more vividly, discussion on the percentage change in the parametric values of different rheological parameters as a sign of improvement due to polymer modification is presented later in the following section.

While the DSR high temperature grade test is a strain-controlled test that measures the linear viscoelastic response of the asphalt binder, the MSCR test is a stress-controlled test that measures both the viscoelastic and visco-plastic behaviours. The coefficients of variation $(\% \mathrm{CV})$ for the DSR high temperature grade test parameter $\left(G^{*} / \sin (\delta)\right)$, MSCR test parameter $\left(J_{n r}\right)$, and subsequently the CEP parameter performed on two replicates for each binder are presented in Table 5. As can be clearly seen from the table, the CVs for $G^{*} / \sin (\delta)$ of every binder at every temperature, and aging protocol are less than $20 \%$, while a few of CVs for $J_{n r}$ and consequently the CEP parameter are greater than $20 \%$. The differences are attributed to the different modes of loading, resulting in different modes of deformations [1]. 
Table 5. Coefficient of variations (\% CV) of different binder rheological parameters.

\begin{tabular}{|c|c|c|c|c|c|c|c|}
\hline & & $\begin{array}{c}G^{*} / \sin \delta(\mathbf{k P a}) \\
\text { [Unaged } \\
\text { Binders] }\end{array}$ & $\begin{array}{c}G^{*} / \sin \delta(\mathbf{k P a}) \\
\text { [RTFO-Aged } \\
\text { Binders] }\end{array}$ & $\begin{array}{c}J_{n r} \\
\text { at } 0.1 \mathrm{kPa}\end{array}$ & $\begin{array}{c}J_{n r} \\
\text { at } 3.2 \mathrm{kPa}\end{array}$ & $\begin{array}{c}\text { CEP } \\
\text { Parameter at } \\
0.1 \mathrm{kPa}\end{array}$ & $\begin{array}{c}\text { CEP } \\
\text { Parameter at } \\
3.2 \mathrm{kPa}\end{array}$ \\
\hline Binder & Temp & CV (\%) & CV (\%) & CV (\%) & CV (\%) & CV (\%) & CV (\%) \\
\hline \multirow{4}{*}{ PG 64-16 } & $64{ }^{\circ} \mathrm{C}$ & 10.60 & 6.96 & 6.60 & 9.87 & 0.36 & 2.91 \\
\hline & $70{ }^{\circ} \mathrm{C}$ & 7.44 & 8.68 & 17.6 & 17.16 & 8.98 & 8.54 \\
\hline & $76^{\circ} \mathrm{C}$ & 12.86 & 15.71 & 12.2 & 11.2 & 3.55 & 4.55 \\
\hline & $64{ }^{\circ} \mathrm{C}$ & 3.29 & 6.75 & 6.10 & 7.10 & 0.67 & 0.34 \\
\hline \multirow[t]{3}{*}{ PG 70-16 } & $70{ }^{\circ} \mathrm{C}$ & 2.64 & 8.76 & 19.3 & 20.52 & 10.62 & 11.87 \\
\hline & $76{ }^{\circ} \mathrm{C}$ & 3.82 & 10.00 & 22.52 & 23.02 & 12.68 & 13.18 \\
\hline & $64{ }^{\circ} \mathrm{C}$ & 19.19 & 1.10 & 20.00 & 25.85 & 20.96 & 26.87 \\
\hline \multirow[t]{3}{*}{ PG 76-16 } & $70{ }^{\circ} \mathrm{C}$ & 18.82 & 0.62 & 26.37 & 22.26 & 25.77 & 21.66 \\
\hline & $76^{\circ} \mathrm{C}$ & 16.47 & 1.77 & 24.95 & 21.76 & 23.24 & 20.02 \\
\hline & $64{ }^{\circ} \mathrm{C}$ & 13.61 & 8.17 & 4.16 & 25.71 & 4.01 & 17.73 \\
\hline \multirow[t]{3}{*}{ PMB $4 \%$ SBS } & $70{ }^{\circ} \mathrm{C}$ & 9.92 & 4.14 & 29.00 & 15.71 & 25.00 & 11.61 \\
\hline & $76^{\circ} \mathrm{C}$ & 2.53 & 1.65 & 23.88 & 11.00 & 22.27 & 9.35 \\
\hline & $64{ }^{\circ} \mathrm{C}$ & 7.69 & 2.73 & 24.15 & 5.11 & 26.79 & 7.84 \\
\hline \multirow[t]{2}{*}{ PMB 6\% SBS } & $70{ }^{\circ} \mathrm{C}$ & 8.96 & 15.53 & 25.61 & 5.29 & 10.28 & 10.29 \\
\hline & $76{ }^{\circ} \mathrm{C}$ & 8.60 & 2.89 & 20.33 & 4.82 & 23.15 & 7.70 \\
\hline
\end{tabular}

\subsection{Percentage Change (Improvement Due to Polymer Modification)}

A comparison of the percentage increase or decrease (negative which means decrease in the $J_{n r}$ ) as a sign of improvement due to polymer modification at $70{ }^{\circ} \mathrm{C}$ is presented in Figure 4. Based on CEP (with $G^{*} / \sin (\delta)$ of RTFO-aged binders) at $0.1 \mathrm{kPa}$, the improvement in performance between PG 70-16 and PMB 4\% SBS, PG 70-16 and 6\% SBS, and PMB 4\% SBS and PMB 6\% SBS were found to be $928 \%, 1532 \%$ and 59\%, respectively. The same at $3.2 \mathrm{kPa}$ were found to be $450 \%, 949 \%$ and $91 \%$, respectively. Generally, these values are much higher than the corresponding percentage change values based on other parameters, such as $G^{*} / \sin (\delta)$ and $J_{n r}$. The calculations point out that the percentage change values as a sign of improvement due to polymer modification are more pronounced when the high-temperature parameter and non-recoverable creep compliance are combined in one single term, designated as CEP. Therefore, CEP is recommended for observing the true distinction of one binder from another. Given the sensitivity of the CEP parameter to the changes of polymer modifications, this might prove particularly helpful when the difference in polymer percentages between two binders is small. To be confident about this conclusion and to empirically support it, the rutting susceptibility of the asphalt mixtures made with the same binders were evaluated in the SPTs (dynamic modulus and dynamic creep).

This fact serves as the motivation for exploring the relationship of the CEP parameter with asphalt mixture rutting parameters (covered in following sections). 


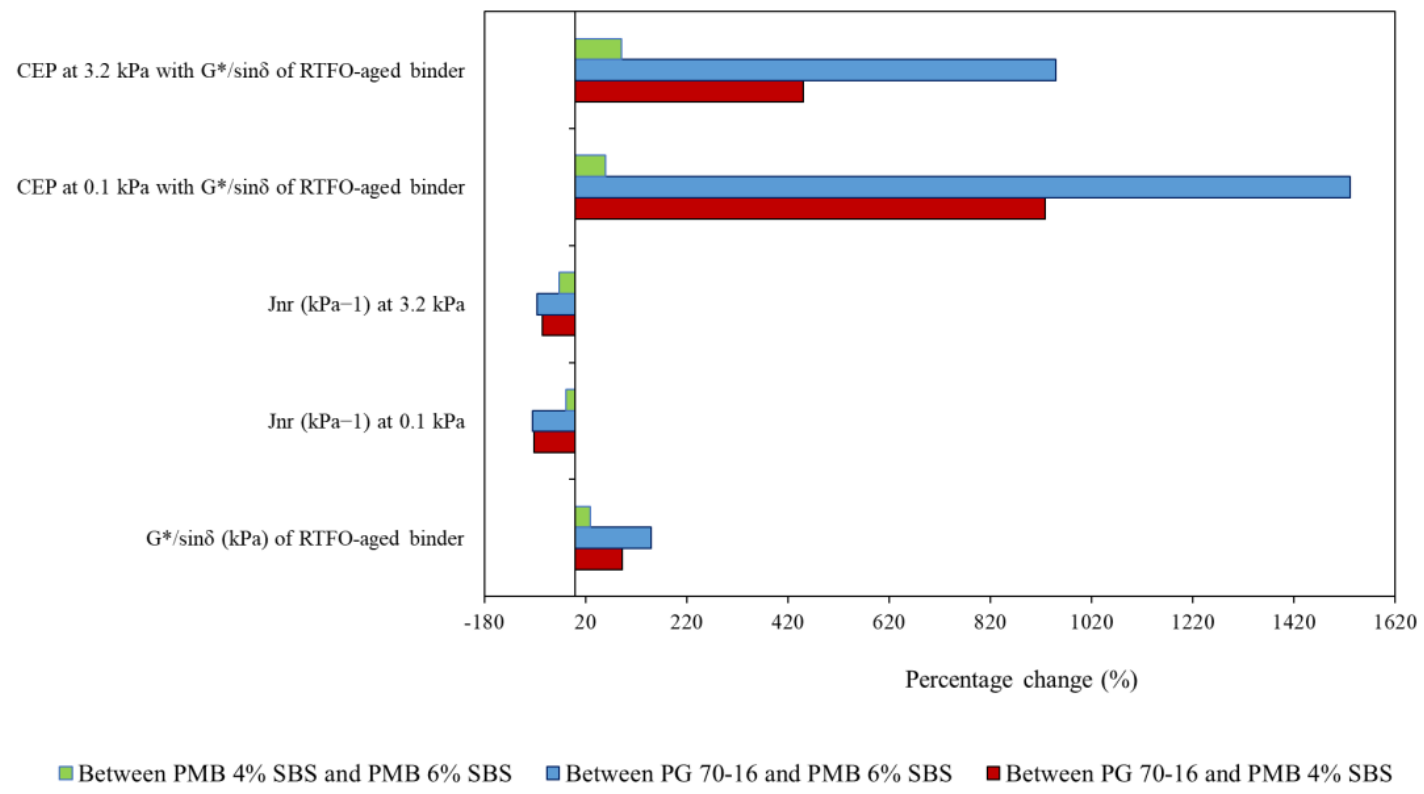

Figure 4. Percentage change of rheological parameters.

\section{Asphalt Mixture Test Results}

As mentioned earlier, three unmodified and two polymer modified asphalt binders were used in this study, and these are PG 64-16, PG 70-16, and PG 76-16, PMB 4\% SBS, and PMB 6\% SBS. A dense-graded HMA AC 14 with nominal maximum aggregate size (NMAS) of $14 \mathrm{~mm}$ was utilised for the production of the cylindrical cores, made with each of the aforementioned binders (two replicates each). The mixes were designated as Mix 1 (PG 64-16), Mix 2 (PG 70-16), Mix 3 (PG 76-16), Mix 4 (PMB 4\% SBS) and Mix 5 (PMB 6\% SBS), and were tested at temperatures $4.4,21.1,37.8$ and $54.4{ }^{\circ} \mathrm{C}$ in the DM test and at 60 ${ }^{\circ} \mathrm{C}$ in the DC test. The volumetric data of the mixture are summarized in Table 6.

Table 6. Asphalt mix volumetric data.

\begin{tabular}{cccccc}
\hline $\begin{array}{c}\text { Aggregate } \\
\text { Content }(\%)\end{array}$ & $\begin{array}{c}\text { Binder } \\
\text { Content }(\%)\end{array}$ & $\begin{array}{c}\text { Target VTM } \\
(\%)\end{array}$ & $\begin{array}{c}\text { Maximum } \\
\text { SG }\left(G_{m m}\right)\end{array}$ & $\begin{array}{c}\text { Bulk SG } \\
\left(G_{m b}\right)\end{array}$ & VMA (\%) \\
\hline 94.9 & 5.1 & 41 & 2.47 & 2.36 & 14.8
\end{tabular}

Note. VTM: Voids in Total Mix; SG: Specific Gravity; VMA: Voids in Mineral Aggregate.

\subsection{Dynamic Modulus (DM) Test Results}

As discussed earlier, the data obtained from DM testing were utilised to construct the master curves for each mixture, which are shown in Figure 5. Higher values of $\left|E^{*}\right|$ correspond to higher stiffness of asphalt mixture, thereby better rut-resistant and vice versa $[6,32,33]$. The DM test results revealed that the coefficient of variation (CV \%) across the temperatures and loading frequency ranged from 3-24\%.

From Figure 5, it can be perceived that the sample with PMB 6\% SBS binder exhibits higher $\left|E^{*}\right|$ values at higher temperatures followed by those made with PMB 4\% SBS, PG 76-16, PG 70-16 and PG 64-16, as may be expected. 


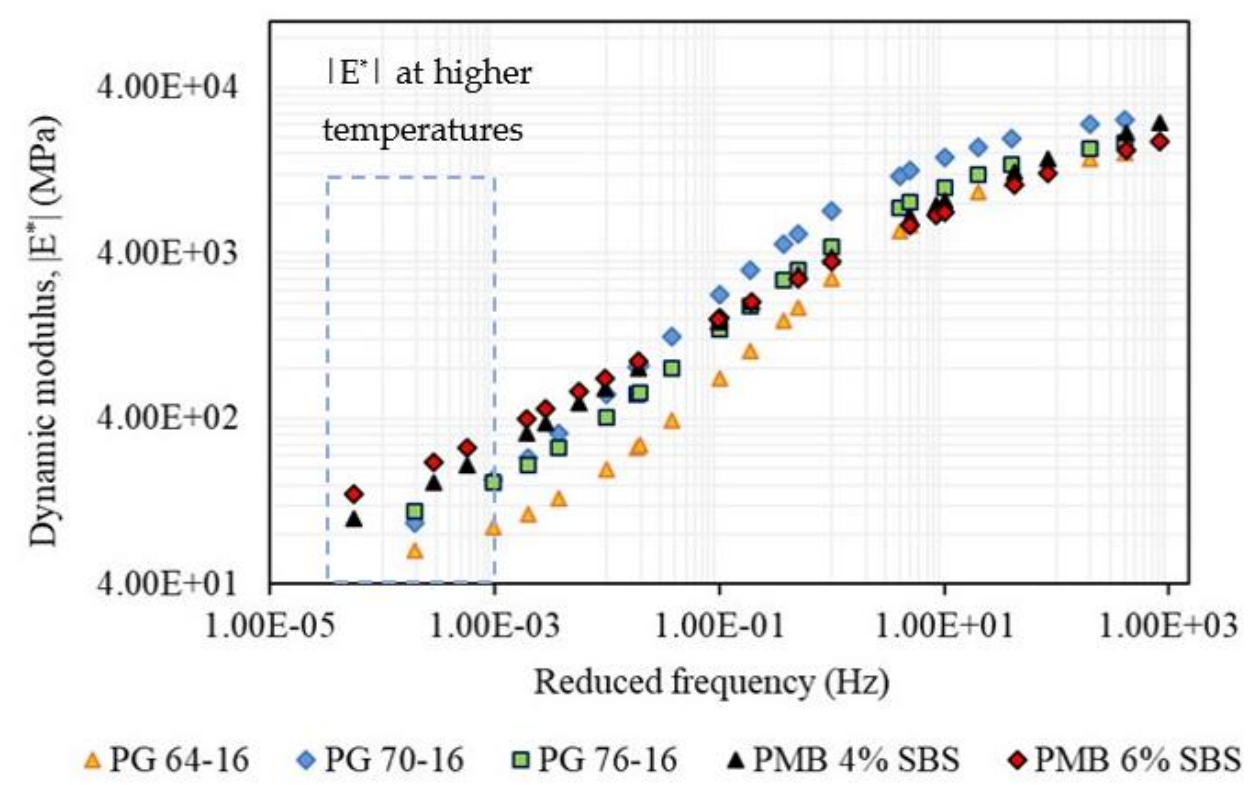

Figure 5. Dynamic Modulus master curves for the five mixes.

\subsection{Dynamic Creep Test Results}

Amongst the asphalt mixes made with unmodified binders, Mix 3 is expected to be the highest rut resistant, followed by Mix 2 and Mix 1, due to the use of PG 76-16, PG 70-16 and PG 64-16, respectively, with all other factors being the same for the three mixes. Likewise, amongst the asphalt mixes made with polymer modified binders, Mix 5 is expected to be highest rut resistant, followed by Mix 4, due to the use of $6 \%$, and $4 \%$ SBS, respectively. The result of the Dynamic Creep test is presented in Table 7, which shows that the overall ranking based on the said parameters exhibited a ranking of Mix $5>$ Mix $4>$ Mix $3>$ Mix $2>$ Mix 1. Representative permanent strain curves of the five mixtures tested in Dynamic Creep test are presented in Figure 6. The results clearly demonstrate that there is a considerable difference between the Flow Number (FN) values of Mix 4 (PMB 4\% SBS) and Mix 5 (PMB 6\% SBS), which should in fact reflect on the binder rheological results. The ranking indicates that $G^{*} / \sin (\delta)$ could not capture the polymer modification, and that, it seems to have underestimated the rut resistance of PMB 4\% SBS and PMB 6\% SBS for unaged and short-term aged binders respectively. In light of this, it can be seen that unlike $G^{*} / \sin (\delta)$, the ranking of binders based on $J_{n r}$ and the CEP bears an exact match with the dynamic creep ranking of the asphalt mixtures based on FN. However, $J_{n r}$ produced results that could not clearly distinguish PMB 4\% SBS and PMB 6\% SBS binders. Therefore, as discussed earlier, due to the insufficiency of $J_{n r}$ as to making a true distinction between the binders, the correlations of the same and CEP with asphalt mixture rutting parameters were explored in the following section.

Table 7. FN results of the five mixes from Dynamic Creep test.

\begin{tabular}{cccc}
\hline $\begin{array}{c}\text { Mix ID with } \\
\text { BINDER }\end{array}$ & $\begin{array}{c}\text { Average FN from the } \\
\text { Dynamic Creep Test }\end{array}$ & SD & CV (\%) \\
\hline Mix 1 (PG 64-16) & 104 & 10.71 & 10.30 \\
Mix 2 (PG 70-16) & 241 & 34.00 & 14.10 \\
Mix 3 (PG 76-16) & 321 & 34.28 & 10.68 \\
Mix 4 (PMB 4\% SBS) & 1083 & 33.17 & 3.06 \\
Mix 5 (PMB 6\% SBS) & 7332 & 1550.00 & 21.12 \\
\hline
\end{tabular}

Note. FN: Flow Number; SD: Standard Deviation; CV: Coefficient of Variation. 


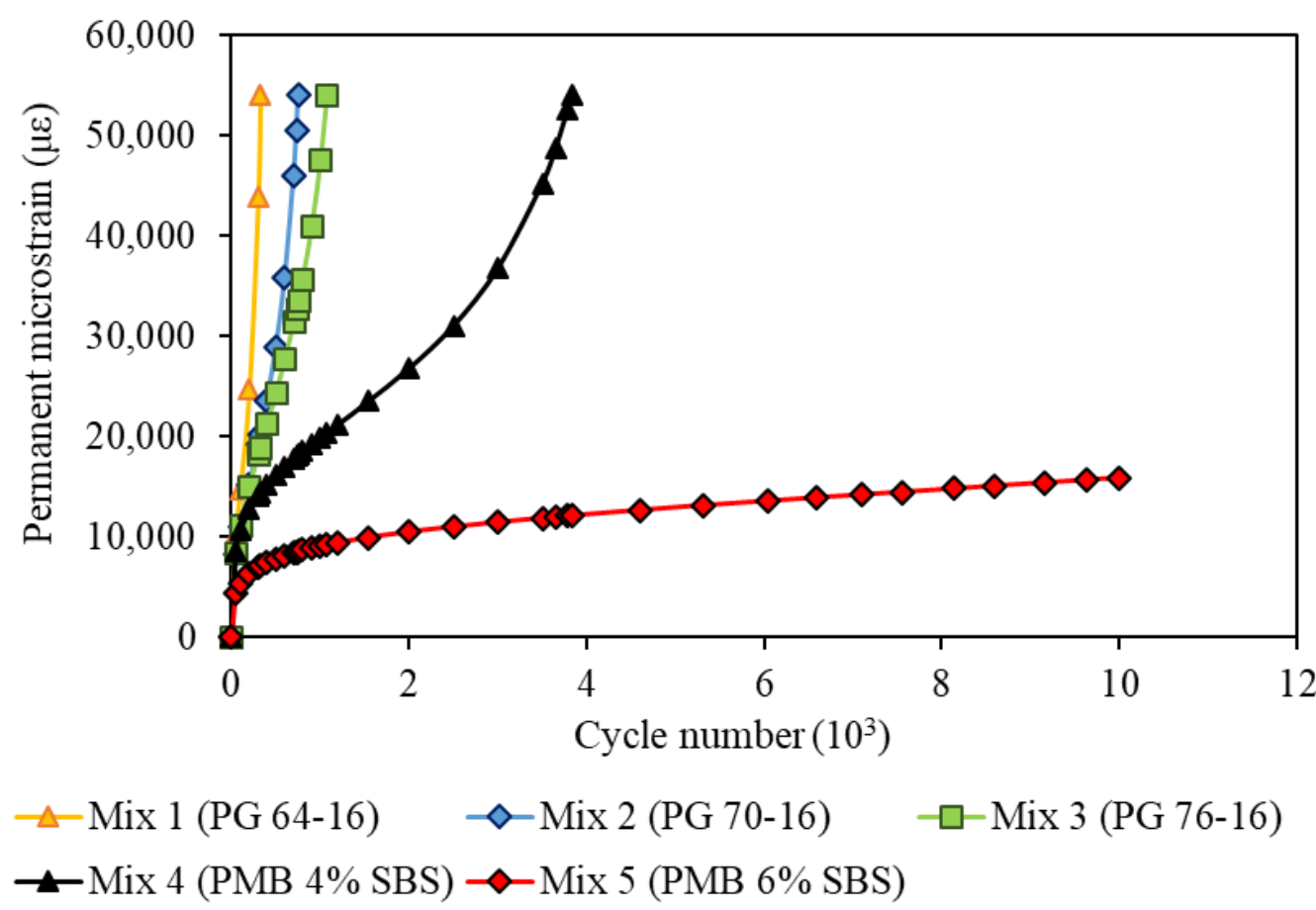

Figure 6. Representative permanent strain curves of the five mixtures tested in Dynamic Creep test.

\section{Relationship of Binder Rheological Parameters and Permanent Deformation Behaviour of the Mixes}

Figure 7a,b depicts the relationship of Flow Number (FN) from dynamic creep test with $J_{n r}$ and CEP parameter at two stress levels $0.1 \mathrm{kPa}$ and $3.2 \mathrm{kPa}$. It can be clearly observed that although $J_{n r}$ of the asphalt binders revealed an expected trend that matches with the FN values of the asphalt mixtures, it offers a narrow range of values. As discussed earlier, based on $J_{n r}$ results, the graphical representation in this section points out that the difference in PMB 4\% SBS and PMB 6\% SBS binders is marginal and is not comparable with asphalt mixture test results. On the other hand, CEP parameter revealed a wider range of values, and the distinction between PMB 4\% SBS and PMB 6\% SBS binders is more pronounced and comparable with asphalt mixture test results.

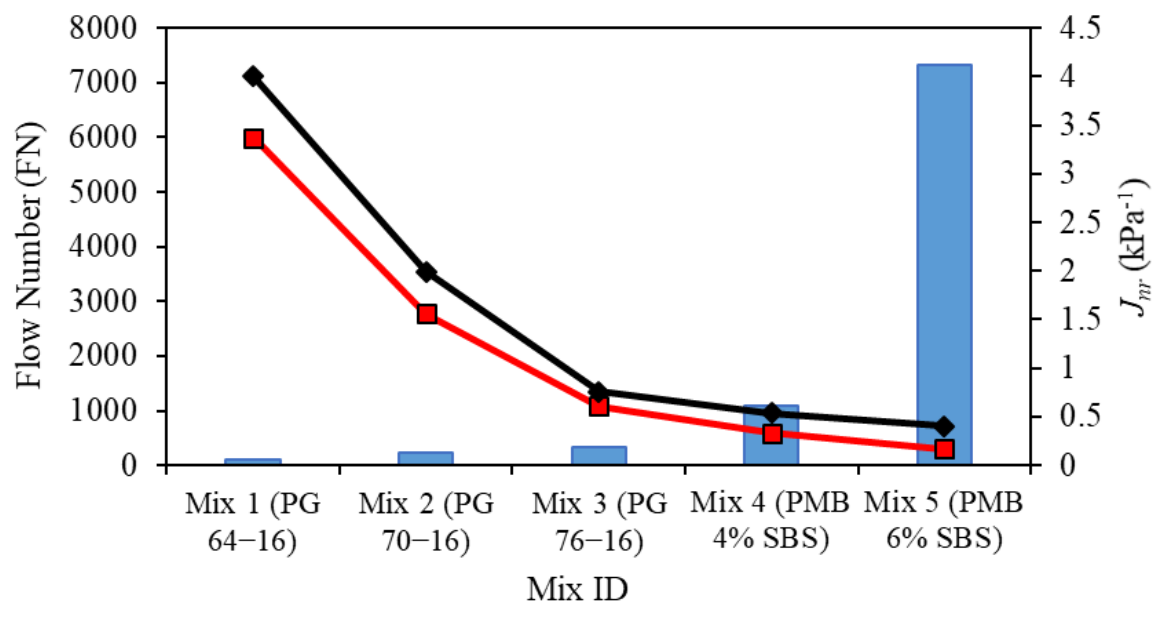

Flow Number (FN) Jnr at $0.1 \mathrm{kPa}$ Jnr at $3.2 \mathrm{kPa}$

(a)

Figure 7. Cont. 


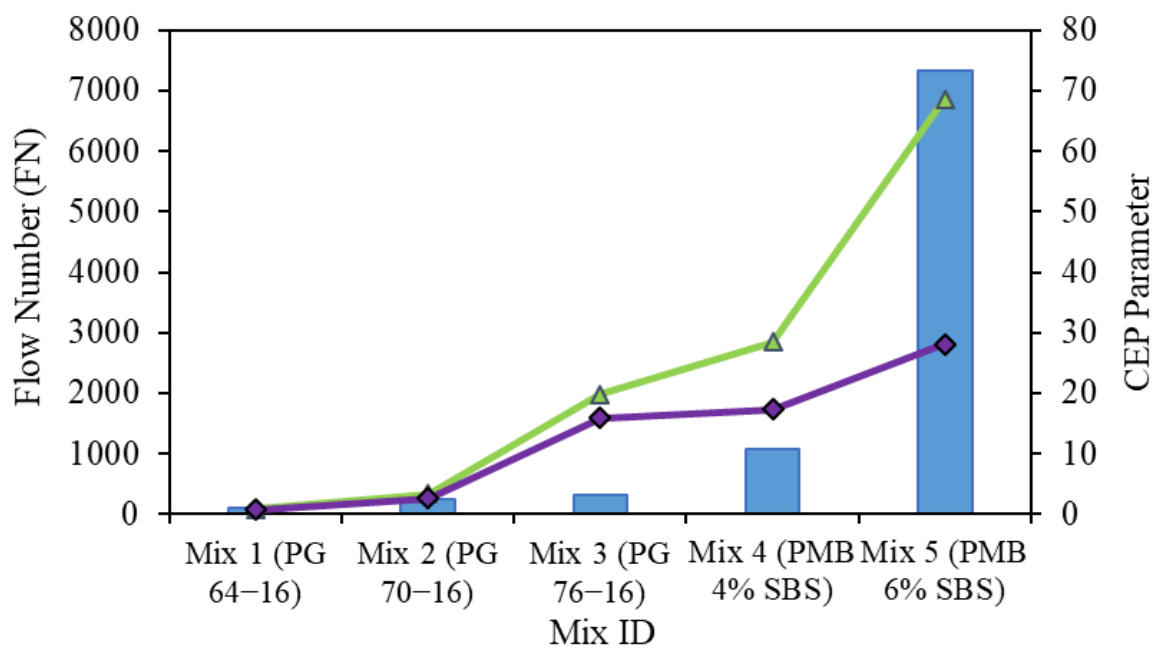

$\square$ Flow Number (FN)

$\triangle-$ CEP Parameter at $0.1 \mathrm{kPa}$

$\prec$ CEP Parameter at $3.2 \mathrm{kPa}$

(b)

Figure 7. Relationship of Flow Number (FN) with (a) $J_{n r}$ and (b) CEP parameter at $64{ }^{\circ} \mathrm{C}$.

As it has been shown earlier that $G^{*} / \sin (\delta)$ is insufficient in characterizing the rutting susceptibility of the polymer modified binders $[1,6,12]$, and that, $J_{n r}$ is preferred over $G^{*} / \sin (\delta)$ for rutting characterisation of asphalt binders, this research mainly focuses on the investigation of the relationship of $J_{n r}$ and CEP with asphalt mix rutting parameters. The analysis presented in this section covers the correlations of only $J_{n r}$ and CEP parameter with DM test results, and the correlations of all three rheological parameters, i.e., $G^{*} / \sin (\delta)$, $J_{n r}$ and CEP parameter with FN values from dynamic creep test.

The graphical correlations between DM $\left(\left|E^{*}\right|\right)$ of the asphalt mixtures and the binder rheological rutting parameters are presented in Figure 8a-d. The binder rheological parameters utilised are $J_{n r}$ and CEP at both $0.1 \mathrm{kPa}$ and $3.2 \mathrm{kPa}$. The rheological parameters at $64{ }^{\circ} \mathrm{C}$ and dynamic modulus values at $54.4{ }^{\circ} \mathrm{C}$ were utilised for the purpose of the correlations. The average values of the respective rutting parameters of each mix were considered. Figure 8 demonstrates that the correlations of CEP at two stress levels 0.1 $\mathrm{kPa}$ and $3.2 \mathrm{kPa}$ with $\left|E^{*}\right|$ at different temperatures and loading frequencies are higher than those for $J_{n r}$ at $0.1 \mathrm{kPa}$ and $3.2 \mathrm{kPa}$ with $\left|E^{*}\right|$ at the corresponding temperature and frequencies. 


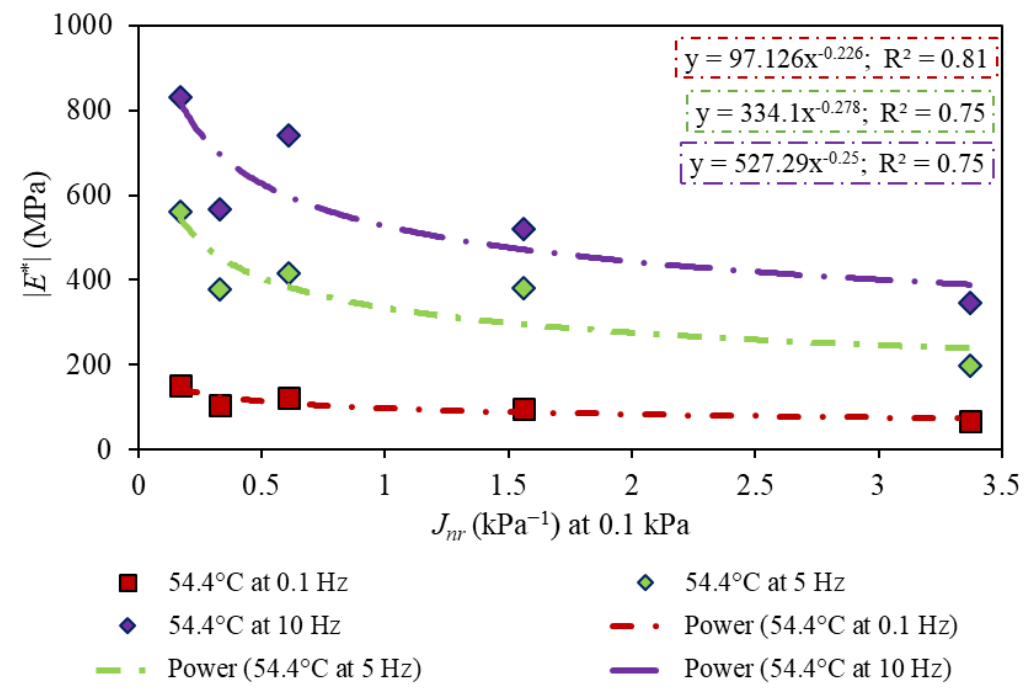

(a)

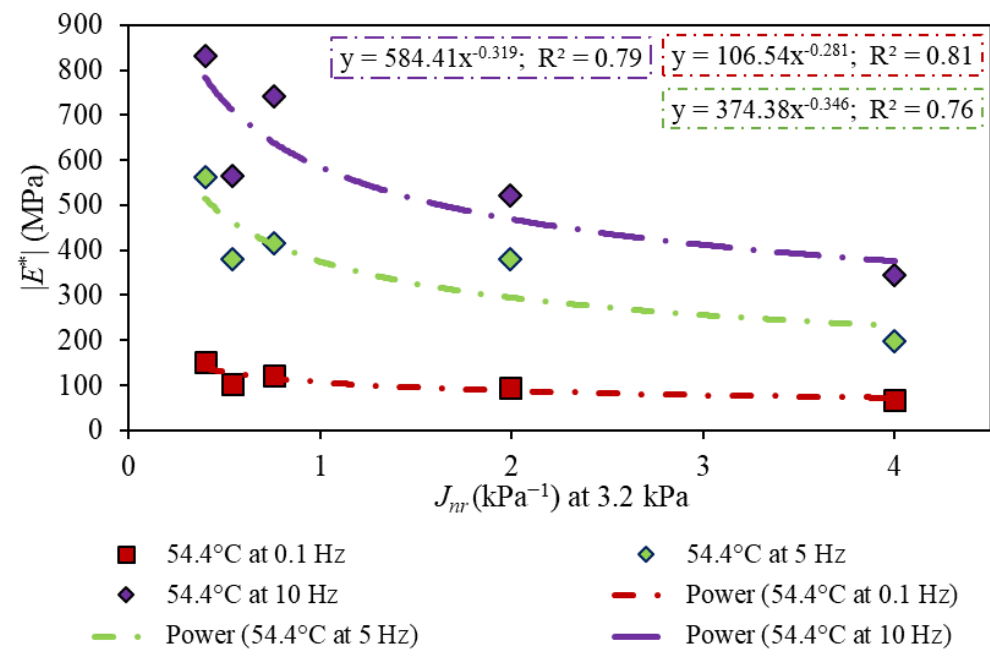

(b)

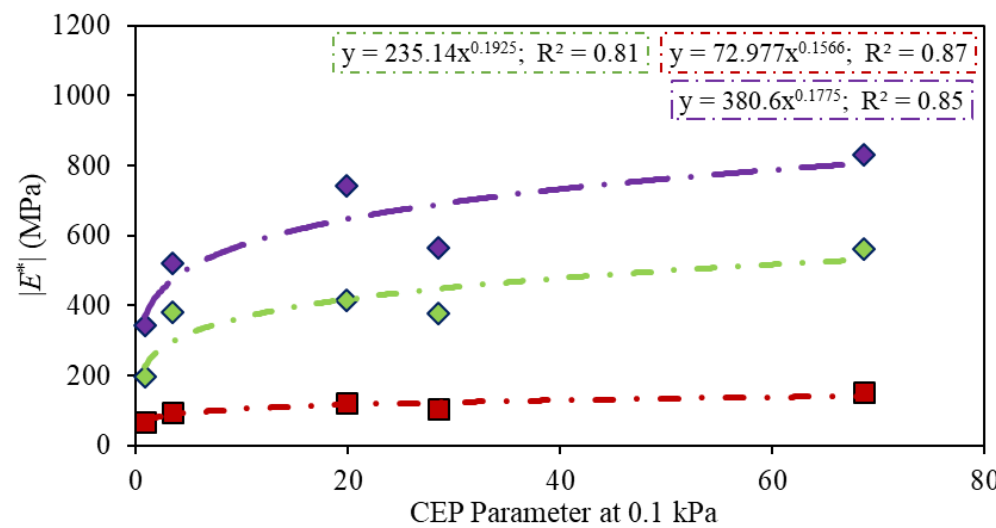

口 $54.4^{\circ} \mathrm{C}$ at $0.1 \mathrm{~Hz}$

- $54.4^{\circ} \mathrm{C}$ at $10 \mathrm{~Hz}$

$\diamond \quad 54.4^{\circ} \mathrm{C}$ at $5 \mathrm{~Hz}$

- Power $\left(54.4^{\circ} \mathrm{C}\right.$ at $\left.5 \mathrm{~Hz}\right)$

- Power $\left(54.4^{\circ} \mathrm{C}\right.$ at $\left.0.1 \mathrm{~Hz}\right)$

- Power $\left(54.4^{\circ} \mathrm{C}\right.$ at $\left.10 \mathrm{~Hz}\right)$

(c)

Figure 8. Cont. 


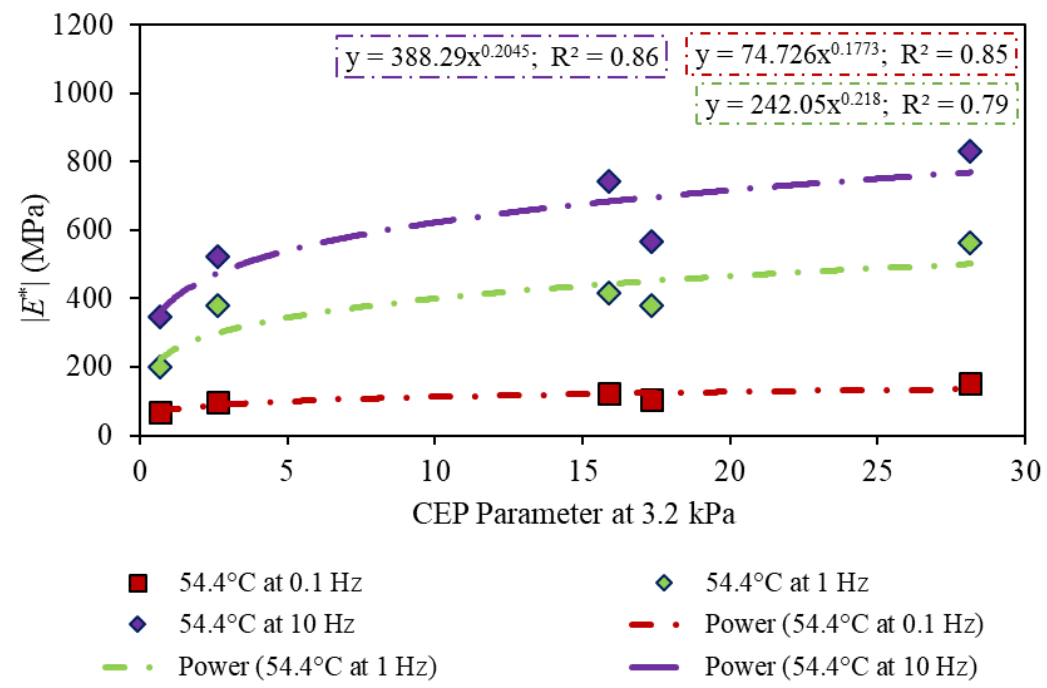

(d)

Figure 8. Correlations of asphalt mix rutting parameters from the Dynamic Modulus test with (a) $J_{n r}$ at $0.1 \mathrm{kPa},(\mathbf{b}) J_{n r}$ at $3.2 \mathrm{kPa},(\mathbf{c})$ CEP parameter at $0.1 \mathrm{kPa}$, and (d) CEP parameter at $3.2 \mathrm{kPa}$.

As the Dynamic Creep test was performed at $60{ }^{\circ} \mathrm{C}$, FN values at $60{ }^{\circ} \mathrm{C}$ and rheological parameters at 64 and $70{ }^{\circ} \mathrm{C}$ were considered for the correlations. Figure $9 \mathrm{a}-\mathrm{c}$ shows that the correlations of FN from dynamic creep test with CEP were found higher than that with individual parameters, i.e., $G^{*} / \sin (\delta)$ and $J_{n r}$. This can be attributed to the fact, that the combination of the two parameters which represent the elastic and plastic behaviours of the asphalt binders gives a greater confidence and shows better relationship with the asphalt mixture rutting characteristics. In this regard, it can be said that the incorporation of more binders, especially the binders modified with different types of additives should reveal a more pronounced contrast in the relationship of $J_{n r}$ and CEP with asphalt mixture rutting parameters. Results from this study encourage that CEP parameter can be considered for true characterisation of asphalt binder because of its ability to distinguish the binders more markedly than any other rheological parameters. This can possibly address and eliminate the overdesigning issues, thereby reducing the material costs. Overall, the results demonstrate the applicability of the CEP as a potential supplementary parameter to the existing Superpave high-temperature $\left(G^{*} / \sin \delta\right)$ and MSCR test parameter $\left(J_{n r}\right)$, in particular for modified binders. 


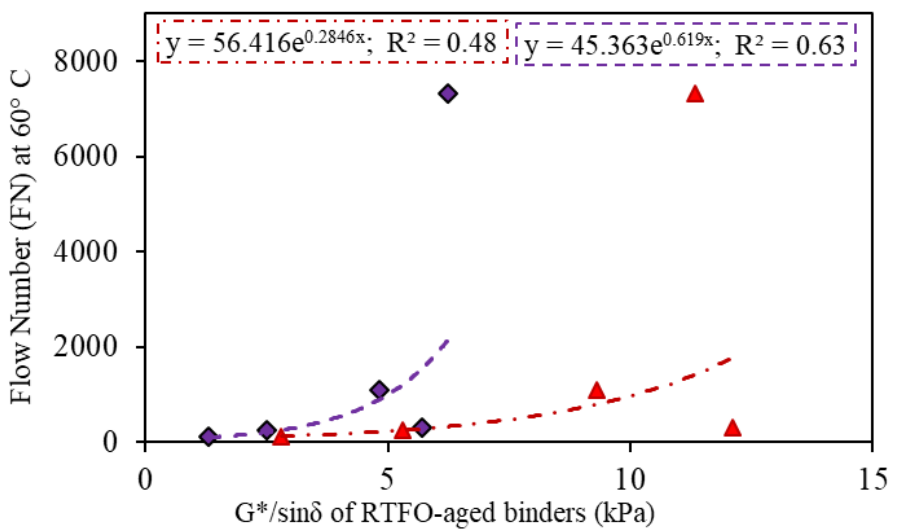

$\Delta \mathrm{G}^{*} / \sin \delta$ at $64^{\circ} \mathrm{C} \quad \diamond \mathrm{G}^{*} / \sin \delta$ at $70^{\circ} \mathrm{C}$

- - Expon. $\left(\mathrm{G}^{*} / \sin \delta\right.$ at $\left.64^{\circ} \mathrm{C}\right) \quad---$ Expon. $\left(\mathrm{G}^{*} / \sin \delta\right.$ at $\left.70^{\circ} \mathrm{C}\right)$

(a)

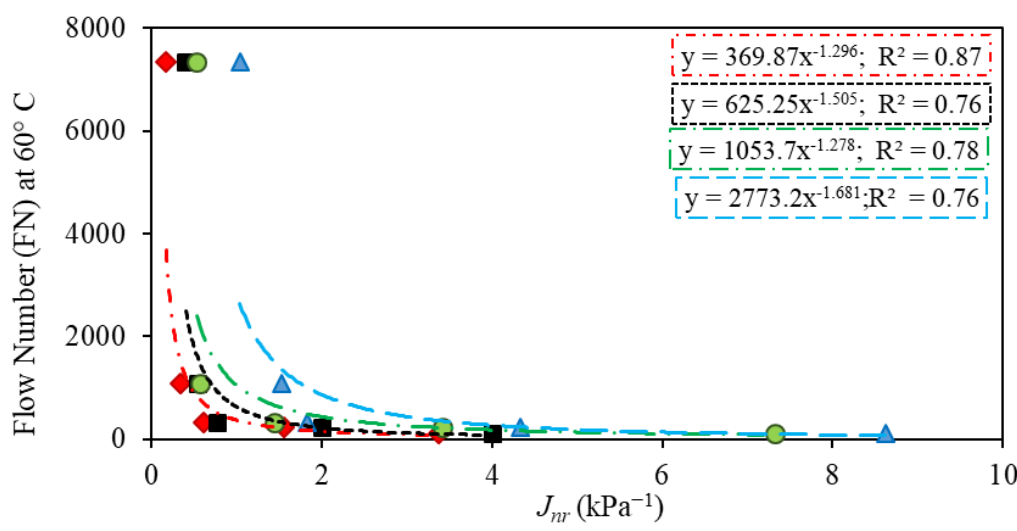

- Jnr at $0.1 \mathrm{kPa}$ at $64^{\circ} \mathrm{C}$ and $\mathrm{FN} \quad \mathrm{Jnr}$ at $3.2 \mathrm{kPa}$ at $64^{\circ} \mathrm{C}$ and $\mathrm{FN}$

- Jnr at $0.1 \mathrm{kPa}$ at $70^{\circ} \mathrm{C}$ and $\mathrm{FN} \Delta \mathrm{Jnr}$ at $3.2 \mathrm{kPa}$ at $70^{\circ} \mathrm{C}$ and $\mathrm{FN}$

-. - Power (Jnr at $0.1 \mathrm{kPa}$ at $64^{\circ} \mathrm{C}$ and $\left.\mathrm{FN}\right)$----- Power (Jnr at $3.2 \mathrm{kPa}$ at $64^{\circ} \mathrm{C}$ and $\mathrm{FN}$ )

- - - Power (Jnr at $0.1 \mathrm{kPa}$ at $70^{\circ} \mathrm{C}$ and $\left.\mathrm{FN}\right)--$ Power (Jnr at $3.2 \mathrm{kPa}$ at $70^{\circ} \mathrm{C}$ and $\mathrm{FN}$ )

(b)

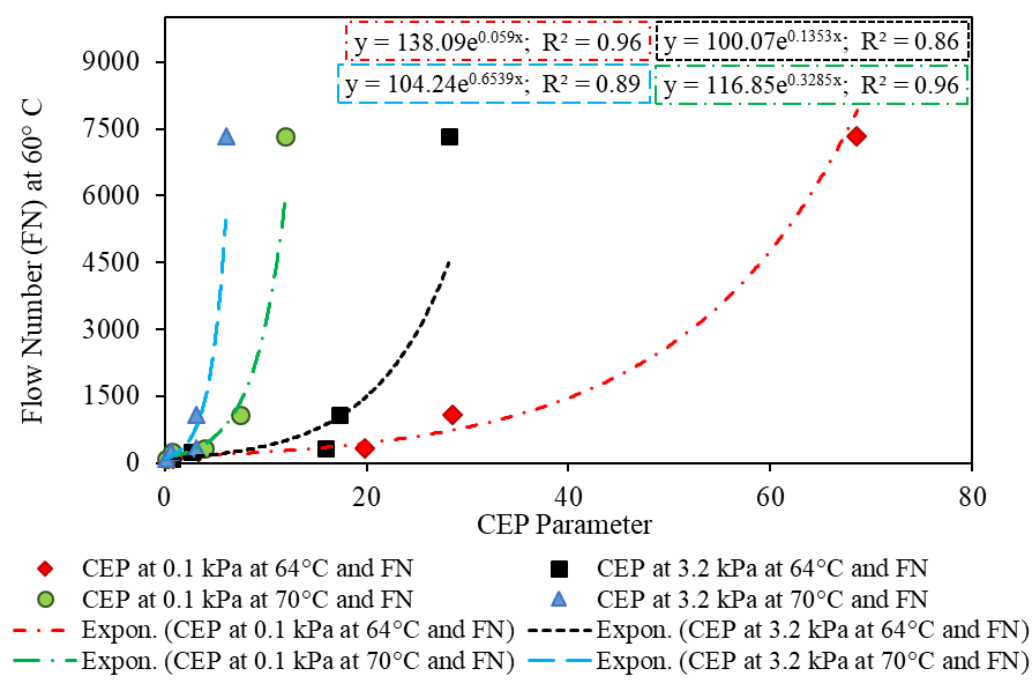

(c)

Figure 9. Correlations of Flow Number (FN) from the Dynamic Creep test with (a) $\mathrm{G}^{*} / \sin (\delta)$, (b) $J_{n r}$, and (c) CEP parameter. 


\section{Conclusions} study:

The following can be concluded based on the results and discussions presented in this

1. The percentage change values in rheological parameters as a sign of improvement due to the increase in SBS polymer content are more pronounced when the hightemperature parameter and non-recoverable creep compliance are combined in one single term, designated as CEP parameter.

2. $J_{n r}$ parameter is less sensitive compared to the CEP parameter and it was observed that the $J_{n r}$ parameter alone could not clearly distinguish between PMB $4 \%$ SBS and PMB 6\% SBS binders, and the distinction is not comparable with the asphalt mixture tests results. On the other hand, CEP parameter revealed a wider range of values, and the distinction between PMB 4\% SBS and PMB 6\% SBS binders based on this parameter is much clearer and comparable with asphalt mixture test results.

3. For the mix gradation and binders utilised in this study, the CEP was found to be more reliable than the $J_{n r}$ parameter for evaluating the rutting performance/resistance of asphalt binders, as better correlations of CEP were found with the asphalt mix performance evaluated in the DM and DC tests.

4. The incorporation of more modified binders in future studies should reveal a more pronounced contrast in the relationship of $J_{n r}$ and CEP with asphalt mixture rutting parameters.

5. This study is limited to the use of only one dense-graded HMA. Therefore, it is recommended that more mix gradations (gap/open/semi-open) should be studied to further supplement the findings reported herein.

Author Contributions: Conceptualization, A.B.R.-C. and M.F.S.; methodology, A.B.R.-C. and M.F.S.; software, A.B.R.-C.; validation, A.B.R.-C., M.F.S. and M.M.-G.; formal analysis, A.B.R.-C. and M.F.S.; data curation, A.B.R.-C. and M.F.S.; writing-original draft preparation, A.B.R.-C.; writing-review and editing, A.B.R.-C., M.F.S. and M.M.-G.; supervision, M.F.S., M.M.-G.; funding acquisition, A.B.R.C. All authors have read and agreed to the published version of the manuscript.

Funding: $75 \%$ of the APC was funded by the University of Canterbury Library, and the remaining $25 \%$ was funded by the Department of Civil and Natural Resources Engineering, University of Canterbury, Christchurch, New Zealand.

Data Availability Statement: Data is contained within the article.

Acknowledgments: The authors would like to acknowledge the staff from Fulton Hogan in Christchurch for supplying the materials utilised in this study. John Kooloos, the technical officer of the Pavement Research Laboratory is particularly acknowledged for his constant help in the production of the samples, and for useful advices.

Conflicts of Interest: The authors declare no conflict of interest. The funders had no role in the design of the study; in the collection, analyses, or interpretation of data; in the writing of the manuscript, or in the decision to publish the results.

\section{References}

1. Zhang, J.; Walubita, L.F.; Faruk, A.N.M.; Karki, P.; Simate, G.S. Use of the MSCR test to characterize the asphalt binder properties relative to HMA rutting performance-A laboratory study. Constr. Build. Mater. 2015, 94, 218-227. [CrossRef]

2. Polaczyk, P.; Ma, Y.; Xiao, R.; Hu, W.; Jiang, X.; Huang, B. Characterization of aggregate interlocking in hot mix asphalt by mechanistic performance tests. Road Mater. Pavement Des. 2021, 22, S498-S513. [CrossRef]

3. Saleh, M. Modified Wheel Tracker as a Potential Replacement for the Current Conventional Wheel Trackers. Int. J. Pavement Eng. 2018. [CrossRef]

4. Roy-Chowdhury, A.B.; Saleh, M.; Moyers-Gonzalez, M. Empirical correlation of the Modified Wheel Tracker (MWT) and the dynamic creep test for evaluating the permanent deformation of HMA. Can. J. Civ. Eng. 2021. [CrossRef]

5. Ishaq, M.A.; Venturini, L.; Giustozzi, F. Correlation Between Rheological Rutting Tests on Bitumen and Asphalt Mix Flow Number. Int. J. Pavement Res. Technol. 2021. [CrossRef]

6. Witczack, M.W.; Kaloush, K.; Pellinen, T.; El-Basyouny, M.; Von Quintus, H. NCHRP Report 465: Simple Performance Test for Superpave Mix Design; Transportation Research Board: Washington, DC, USA, 2002. 
7. Javilla, B.; Fang, H.; Mo, L.; Shu, B.; Wu, S. Test evaluation of rutting performance indicators of asphalt mixtures. Constr. Build. Mater. 2017, 155, 1215-1223. [CrossRef]

8. Shenoy, A. Refinement of the Superpave specification parameter for performance grading of asphalt. J. Transp. Eng. 2001, 127, 357-362. [CrossRef]

9. Shenoy, A. A comprehensive treatise of the high temperature specification parameter $G^{*} /(1-(1 / \tan \delta \sin \delta))$ for performance grading of asphalts. Appl. Rheol. 2004, 14, 303-314. [CrossRef]

10. Shenoy, A. High temperature performance grading of asphalts through a specification criterion that could capture field performance. J. Transp. Eng. 2004, 1, 132-137. [CrossRef]

11. Singh, D.; Kataware, A.V. Comparison of different rheological parameters for rutting susceptibility of SBS+WMA modified binders. Innov. Infrastruct. Solut. 2016, 1, 28. [CrossRef]

12. D'Angelo, A. The relationship of the MSCR test to rutting. Road Mater. Pavement Des. 2009, 10, 61-80. [CrossRef]

13. Radhakrishnan, V.; Sri, M.R.; Reddy, K.S. Evaluation of asphalt binder rutting parameters. Constr. Build. Mater. 2018, 173, 298-307. [CrossRef]

14. Ameli, A.; Babagoli, R.; Khabooshani, M.; AliAsgari, R.; Jalali, F. Permanent deformation performance of binders and stone mastic asphalt mixtures modified by SBS/montmorillonite nanocomposite. Constr. Build. Mater. 2020, 239, 117700. [CrossRef]

15. White, G. Grading highly modified binders by multiple stress creep recovery. Road Mater. Pavement Des. 2017, 18, 1322-1337. [CrossRef]

16. Bastos, J.B.S.; Babadopulos, L.F.A.L.; Soares, J.B. Relationship between multiple stress creep recovery (MSCR) binder test results and asphalt concrete rutting resistance in Brazilian roadways. Constr. Build. Mater. 2017, 145, 20-27. [CrossRef]

17. Salim, R.; Gundla, A.; Underwood, B.S.; Kaloush, K.E. Effect of MSCR Percent Recovery on Performance of Polymer Modified Asphalt Mixtures. Transp. Res. Rec. J. Transp. Res. Board 2019, 2673, 309-319. [CrossRef]

18. Behnood, A.; Shah, A.; McDaniel, R.S.; Beeson, M.; Olek, J. High-Temperature Properties of Asphalt Binders: Comparison of Multiple Stress Creep Recovery and Performance Grading Systems. Transp. Res. Rec. J. Transp. Res. Board 2016, 2574, 131-143. [CrossRef]

19. ASTM D7175-15. Standard Test Method for Determining the Rheological Properties of Asphalt Binder Using a Dynamic Shear Rheometer. ASTM Int. 2015. [CrossRef]

20. ASTM D7405-15. Standard Test Method for Multiple Stress Creep and Recovery (MSCR) of Asphalt Binder Using a Dynamic Shear Rheometer. ASTM Int. 2015. [CrossRef]

21. Bonaquist, R.F. NCHRP Report 614: Refining the Simple Performance Tester for Use in Routine Practice; Transportation Research Board: Washington, DC, USA, 2008.

22. Pellinen, T.K.; Witczak, M.W. Stress dependent master curve construction for dynamic (complex) modulus. J. Assoc. Asph. Paving Technol. 2002, 71, 281-309.

23. Lu, S.D.; Saleh, M. Evaluation of warm mix asphalt performance incorporating high RAP content. Can. J. Civ. Eng. 2016, 43, 343-350. [CrossRef]

24. Lu, D.X.; Saleh, M. Laboratory evaluation of warm mix asphalt incorporating high RAP proportion by using evotherm and sylvaroad additives. Constr. Build. Mater. 2016, 114, 580-587. [CrossRef]

25. Elseifi, M.A.; Mohammad, L.N.; Kassem, E.; Ying, H.; Masad, E. Damage in asphalt concrete during the dynamic complex modulus and flow number tests. In Asphalt Pavements; Kim, Y.R., Ed.; Taylor \& Francis Group: London, UK, 2014; ISBN 978-1-138-02693-3.

26. AASHTO T 378-17. Standard Method of Test for Determining the Dynamic Modulus and Flow Number for Asphalt Mixtures Using the Asphalt Mixture Performance Tester (AMPT); AASHTO Standard: Washington, DC, USA, 2017.

27. Airey, G.D. Rheological properties of styrene butadiene styrene polymer modified road bitumens. Fuel 2003, 82, 1709-1719. [CrossRef]

28. Hassanpour-Kasanagh, S.; Ahmedzade, P.; Fainleib, A.M.; Behnood, A. Rheological properties of asphalt binders modified with recycled materials: A comparison with Styrene-Butadiene-Styrene (SBS). Constr. Build. Mater. 2020, 230, 117047. [CrossRef]

29. Alnaqbi, A.; Zeiada, W.; Al-Khateeb, G.; Ezzat, H.; Shanableh, A. Effect of Styrene-Butadiene-Styrene on the Properties and Grading of Local Asphalt Binder in the UAE. IOP Conf. Ser. Mater. Sci. Eng. 2021, 1044, 012003. [CrossRef]

30. AS/NZS 2891.2.1. Methods of sampling and testing asphalt. In Part 2.1: Sample Preparation-Mixing, Quartering and Conditioning of Asphalt in the Laboratory; SAI Global Limited under Licence from Standards Australia: Sydney, Australia, 2014.

31. AS/NZS 2891.2.2. Methods of sampling and testing asphalt. In Part 2.2: Sample Preparation-Compaction of Asphalt Test Specimens Using a Gyratory Compactor; SAI Global Limited under Licence from Standards Australia: Sydney, Australia, 2014.

32. Hu, S.; Zhou, F.; Scullion, T. Development, calibration, and validation of a new M-E rutting model for HMA overlay design and analysis. J. Mater. Civ. Eng. 2011, 23, 89-99. [CrossRef]

33. Goh, S.W.; You, Z.; Williams, R.C.; Li, X. Preliminary dynamic modulus criteria of HMA for field rutting of asphalt pavements: Michigan's experience. J. Transp. Eng. 2011, 137, 37-45. [CrossRef] 